\title{
A relação entre os princípios da eficiência e da economicidade nos contratos administrativos
}

\author{
Letícia Malta Araújo e Maria Isabel Araújo Rodrigues
}

\section{Introdução}

A Constituição da República de 1988 (CRF/1988) determinou como regra a obrigatoriedade do processo licitatório para toda administração pública, direta, indireta e fundacional nos termos do seu artigo 37, inciso XXI, visando alcançar a proposta mais vantajosa financeiramente e tecnicamente para os interesses da administração no âmbito de suas contratações.

Nesse contexto, destacam-se os princípios da eficiência e da economicidade no que se refere às licitações e aos contratos formalizados pela administração pública. Isso porque tais princípios zelam, respectivamente, por aperfeiçoar a alocação dos recursos públicos nas contratações e por alcançar a alternativa mais vantajosa do ponto de vista econômico. O primeiro foi incluído na Carta Magna pela Emenda Constitucional no 19 de 1998, que cuidou da reforma administrativa do Estado brasileiro, enquanto o segundo encontra-se previsto no Artigo 70 da CRF/1988. 
A efetiva observância pela administração pública desses dois princípios em uma mesma contratação é um desafio diante do qual se deparam seus administradores. Admitindo-se como finalidade das licitações a seleção da proposta mais vantajosa financeiramente e tecnicamente para a administração, a inobservância de um desses princípios da administração pública no processo tem o potencial de comprometer $\mathrm{o}$ alcance de tal finalidade.

O administrador público se depara muitas vezes com um conflito de escolha no que diz respeito às possibilidades de priorizar em uma contratação o princípio da eficiência ou aquele da economicidade, podendo comprometer a conformidade do processo com o ordenamento jurídico (que prevê tais princípios) e, consequentemente, o cumprimento do postulado da legalidade.

O presente artigo analisou os contratos celebrados pela Secretaria de Estado de Turismo de Minas Gerais (Setur) durante os exercícios dos anos de 2008 e 2009, de forma a averiguar a ocorrência ou não de sobreposição do princípio da economicidade ao da eficiência. Acredita-se que esta análise possa se estender aos demais contratos administrativos formalizados pela administração pública, posto que a maioria das cláusulas constantes neles decorrem da Lei Federal no 8.666/1993.

Inicialmente, este artigo exporá os principais aspectos referentes à Teoria dos Princípios, bem como ao processo de reforma do Estado. Em seguida, serão analisados os conceitos e regras aplicáveis aos contratos administrativos, além das proposições básicas acerca dos princípios da administração pública, especialmente no que se refere aos princípios da eficiência e da economicidade.

Far-se-á, ainda, a análise da relação entre os princípios da eficiência e da economici- dade nos contratos de serviços celebrados pela Setur em 2008 e 2009, a partir dos resultados obtidos pelas entrevistas realizadas com os gestores de tais contratos, bem como pela comparação entre os valores contratuais e os referentes aos preços praticados no mercado. Por fim, serão apresentadas conclusões acerca dos resultados obtidos e sugeridas determinadas mudanças a serem aplicadas no contexto da fiscalização e do acompanhamento dos contratos celebrados pela Setur.

\section{A teoria dos princípios}

Considerando que a análise se pauta em dois princípios, faz-se necessário uma breve exposição acerca da Teoria dos Princípios. Tendo em vista a tradicional definição dessa teoria, Alexy (2000) preceitua princípios como normas determinantes de algo que seja realizado segundo maior nível de excelência possível, de acordo com as possibilidades que a lei e a própria realidade apresentam. Nessa perspectiva, princípios podem ser definidos como mandamentos de otimização do objetivo que se busca.

No que diz respeito à colisão entre princípios, Alexy (2000) demonstra o fato de existirem relações de prioridade entre eles, de acordo com as condições do caso concreto. Logo, a tarefa de otimizar implica determinar corretamente cada relação de prioridade condicional entre tais normas.

Entretanto, segundo Ávila (2005), Dworkin defende a ideia de que os princípios, diferentemente das regras, não são capazes de determinar a decisão, mas apenas contêm fundamentos que devem ser conjugados com outros fundamentos advindos de outros princípios. Assim, Dworkin distingue princípios e regras por uma diferenciação no que tange à estrutura lógica, por meio de critérios classificatórios. 
Ávila (2005) constata que os princípios permitem a consideração de aspectos concretos e individuais, sem que se constituam obstáculos institucionais. Isto porque os princípios estabelecem um "estado de coisas" que deve ser promovido sem que seja descrito, diretamente, qual o comportamento devido.

Nesse contexto, caso haja colisão total entre princípios, o que de fato ocorre é a impossibilidade de se aplicar um dos princípios para a solução de um problema concreto. Não pode, assim, ser descartada a possibilidade de, em outros casos, o mesmo princípio afastado ser aplicado, podendo até mesmo prevalecer àquele que no primeiro caso prevaleceu a ele. (SILVA, 2003)

\section{A reforma do Estado e o princí- pio da eficiência}

É relevante que a Reforma da Administração Pública no Brasil seja analisada a partir da importância atribuída à necessidade de melhorar a qualidade da prestação de serviço feita pelo Estado brasileiro de maneira a torná-la mais racional e capaz de melhor atender às demandas dos cidadãos.

Como bem enfatizam Pereira e Spink (2006), é necessário introduzir noções de qualidade, produtividade, resultados, responsabilidade dos funcionários, entre outras, na administração pública brasileira. Sendo assim, o ideal de transformar o aparato público brasileiro em uma nova gerência pública teria como objetivos a racionalização da gestão pública, assim como a implantação de uma visão mais econômica no setor.

Nesse sentido, como observa Di Pietro (1999, p. 73), "a reforma do Estado permitirá que seu núcleo estratégico tome decisões mais corretas e efetivas, e que seus serviços - tanto os exclusivos quanto os competitivos, que estarão apenas indireta- mente subordinados na medida em que se transformem em organizações públicas não estatais - operem muito eficientemente". Abrucio (2007) ressalta que a ênfase no princípio da eficiência pode otimizar os recursos à disposição do Estado e dos cidadãos, além de reduzir os gastos governamentais.

Os esforços no sentido de modernizar a execução das ações da administração pública exemplificam o fato de que realizar de maneira eficiente e econômica as fun-

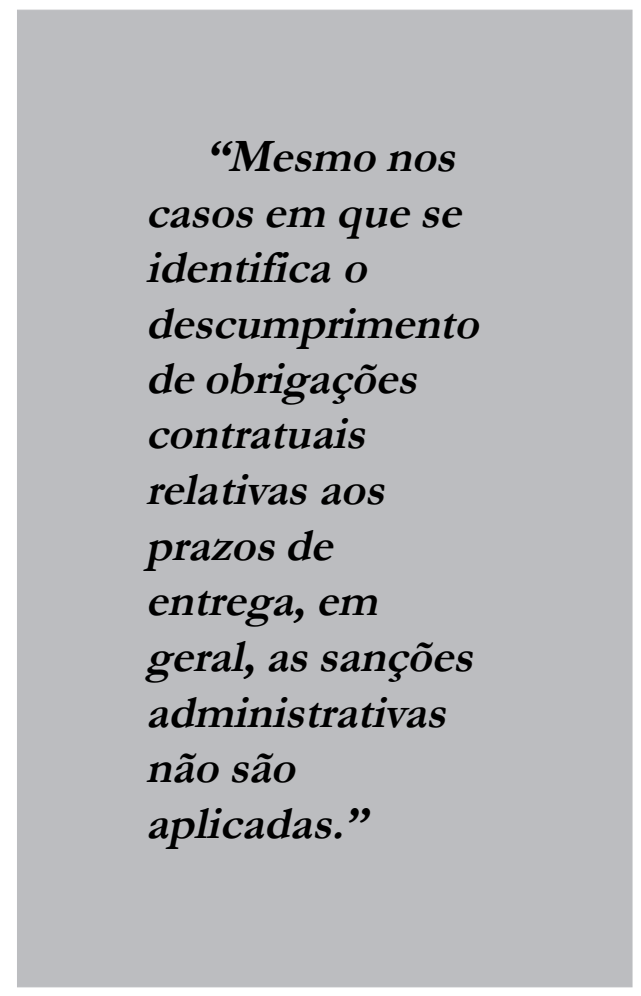

ções atribuídas ao Estado tornou-se uma necessidade nas últimas décadas.

Tal necessidade aplica-se, certamente, ao contexto das licitações e contratos firmados pelo Poder Público. Nesse sentido, no que se refere à busca pela racionalidade em um procedimento licitatório, de acordo com o Tribunal de Contas da União (TCU), poderão ser efetivadas as contratações públicas somente após a estimativa prévia de 
seu valor (BRAsil, 2006). Além disso, o acórdão 1544/2004 do TCU recomenda a realização de pesquisa de preços para verificação das propostas apresentadas com os preços de mercado de acordo com a determinação do art. 43, inciso IV da Lei Federal no 8.666, de 21 de junho de 1993 (BRASIL, 2006).

De breve, nota-se que a adequação do processo licitatório às exigências anteriormente expostas configura-se como um prérequisito para que a administração possa conduzir satisfatoriamente o processo de contratação, isso porque a existência de entraves em um processo licitatório é capaz de comprometer o sucesso de uma contratação pública (Meirelles, 2007).

\section{O contrato administrativo, con- ceito e regras de aplicabilidade}

O contrato administrativo é definido por Meirelles (2007, p. 194) como “o ajuste que a administração pública, agindo nesta qualidade, firma com o particular ou com outra entidade administrativa, para a consecução de objetivos de interesse público, nas condições desejadas pela própria Administração".

É importante ressaltar que, de acordo com Almeida (2009), a administração possui o poder-dever de fiscalizar a execução do contrato administrativo nos moldes do Artigo 58 da Lei Federal $n^{\circ}$ 8.666, de 21 de junho de 1993. Dessa for$\mathrm{ma}, \mathrm{com}$ vistas a melhor satisfazer o interesse público, a administração deve fiscalizar a execução do contrato durante todo o seu curso, sendo tal atribuição um dever, e não uma faculdade. Nos casos em que se constatar a inexecução total ou parcial do contrato, a administração aplicará as sanções correspondentes ao tipo de irregularidade existente. Tais sanções encontram-se previstas nos artigos 86 a 88 do referido dispositivo legal.

O acompanhamento do contrato tem como pressuposto, segundo Almeida (2009), a garantia do atendimento ao princípio da eficiência. Esta atividade consiste em acompanhar o desempenho do fornecedor durante toda a execução contratual de forma a se manter, continuamente, um registro do histórico da qualidade dos serviços ou dos fornecimentos realizados.

A finalidade da atividade de fiscalização contratual, segundo Meirelles,

[...] é assegurar a perfeita execução do contrato, ou seja, a exata correspondência dos trabalhos com o projeto ou com as exigências previamente estabelecidas pela Administração, tanto nos seus aspectos técnicos quanto nos prazos de realização, e, por isso mesmo, há de pautar-se pelas cláusulas contratuais, pelas normas regulamentares do serviço e pelas disposições do caderno de obrigações, se existentes. (MeIrelles, 2007, p. 235)

A administração, segundo Justen Filho (2006), não pode correr o risco de obter a execução defeituosa do contrato e, por isso, deve exercer a fiscalização permanente para verificar se o contratado está adotando as precauções e técnicas necessárias. $\mathrm{O}$ autor também adverte que o Art. 67 da Lei ${ }^{\circ}$ 8.666, de 21 de junho de 1993, prevê a designação de um agente da administração para acompanhar de forma direta a atividade do outro contratante.

Entre as atribuições deste agente encontra-se o acompanhamento do desenvolvimento da atividade do particular, anotando ocorrências relevantes e documentando eventuais imperfeições a serem corrigidas (Justen FiLho, 2006). 
Nota-se, portanto, que a administração não encerra suas atividades referentes ao processo de contratação no momento em que ocorre a assinatura do contrato. A partir dos argumentos apresentados, entendese que durante as etapas de execução e fiscalização contratual o administrador público tem o dever de acompanhar o andamento do contrato aplicando, sempre que necessário, as sanções legalmente previstas. $\mathrm{O}$ acompanhamento do contrato deve ser realizado tendo em vista as obrigações das partes, assim como a observância dos diversos princípios da administração pública.

\section{Princípios da administração pública}

A definição destes princípios implica identificar ideias centrais de um sistema, que estabelecem suas diretrizes e conferem-lhe um sentido lógico, harmonioso e racional, possibilitando uma adequada compreensão de sua estrutura. Sendo assim, eles determinam o alcance e o sentido das regras de um dado subsistema do ordenamento jurídico, de forma a balizar a interpretação e a própria produção normativa (ALEXANDRINO; Paulo, 2010).

Admite-se que toda atividade estatal se encontra vinculada à obediência dos fundamentos e diretrizes previstos constitucionalmente (FrançA, 1999). Nesse sentido, observa-se a necessidade de que os agentes públicos ajam em conformidade com princípios administrativos nas situações em que estes pareçam conflitantes. Consequentemente, os contratos administrativos, tendo em vista o interesse da coletividade, não devem ferir os princípios constitucionais a que a administração está vinculada (SZKLAROWJKY, 1999).

A partir de 1998, a influência da ideologia neoliberal mostrou a necessidade de se realizar uma reforma administrativa no Brasil. Nesse contexto, incluiu-se o princípio da eficiência no rol daqueles já previstos pelo texto constitucional, a saber, os princípios da legalidade, impessoalidade, moralidade e publicidade (MARTINS, [200]). Tal inserção visou à garantia de uma gestão da coisa pública cada vez menos burocrática a fim de atingir seus objetivos de maneira mais rápida e eficaz, correspondendo às demandas sociais.

A inclusão do princípio da eficiência pela Emenda Constitucional no 19 de 1998 teve como objetivo "[...] conferir direitos aos usuários dos diversos serviços prestados pela Administração ou por seus delegados e estabelecer obrigações efetivas aos prestadores [...]". Assim, a inserção desse princípio revela a insatisfação da sociedade frente às dificuldades por ela enfrentadas ao lutar "[...] contra a deficiente prestação de tantos serviços públicos [...]" (Justen Filho, 2006, p. 21).

É necessário salientar a importância do princípio da eficiência, uma vez que "é exigência jurídica, imposta à administração pública e àqueles que lhe fazem as vezes ou simplesmente recebem recursos públicos vinculados de subvenção ou fomento, de atuação idônea, econômica e satisfatória na realização das finalidades públicas que lhes forem confiadas por lei ou por ato ou contrato de direito público." (Modesto apud Coelho, 2004, p. 88).

Segundo Mello (2004), o princípio em comento é capaz de proporcionar aos cidadãos maior capacidade de exercer a cidadania, já que se torna um dever constitucional da administração e, caso seja desrespeitado, devem ser responsabilizados os agentes que derem causa à sua violação.

Batista Júnior (2004) conclui que o princípio da eficiência, sendo uma norma dotada de imperatividade material, traduz 
um mandamento de otimização no Estado Social, de forma a impulsionar a administração a satisfazer as necessidades e os interesses sociais, econômicos e culturais da coletividade. Nesse sentido, tal princípio "[...] entremeia o sistema jurídico com o valor da igualdade material, judicizando, para a Administração Pública, a necessidade de otimização da aplicação dos meios e recursos para o melhor alcance e satisfação possível do bem comum". (BATISTA JúNIOR, 2004, p. 109)

Tendo em vista a análise do princípio da eficiência, torna-se necessário discorrer acerca dos conceitos eficiência, eficácia, e efetividade. Alfonso (apud Alcantara, 2009, p. 34) "considera que a eficiência, fazer bem as coisas, é mais específica e próxima à economia; e a eficácia, fazer as coisas, tem caráter mais administrativo e organizacional. Esta engloba a eficiência e a economia".

Segundo o autor, o conceito de eficiência compreende otimizar a utilização dos meios, ao passo que a eficácia implica produzir os efeitos desejados de forma ótima. Já a efetividade significa a exata produção do efeito que se almejava. (Alfonso apud Pereira, 2007).

No que tange à sua aplicação, observa-se que o princípio da eficiência deve ser observado ao longo de todo o processo de contratação realizado pela administração. É importante que o contrato administrativo satisfaça as necessidades em razão das quais foi assinado, sendo vantajosa a aplicação dos recursos públicos utilizados. Assim sendo, os meios utilizados pelo Poder Público ao contratar devem ser otimizados, de maneira que se obtenha o fim almejado pela administração, e que não haja desperdício de recursos.

Além do princípio da eficiência, importa, ainda, ressaltar a relevância do já con- sagrado princípio da economicidade. Bruno (2008) adverte que a CFR/88 concede autonomia ao princípio da economicidade por meio de seu Art. 70, caput, e a fiscalização de sua observância compete aos órgãos internos e externos de controle da atividade financeira da administração. $\mathrm{O}$ autor lembra que a previsão deste princípio não se constitui inovação trazida pelo texto constitucional, uma vez que o Art. 14 do Decreto Lei n ${ }^{\circ} 200$, de 25 de fevereiro de 1967, já dispunha sobre o assunto.

Ao conceituar o princípio da economicidade, Bruno (2008, p.69) relaciona-o com a " $[. .$.$] análise da relação custo-$ benefício que assegure não haver desperdício de recursos públicos, verificação que deve dar-se na observação da conformidade e do desempenho da opção realizada pelo agente em relação aos resultados efetivamente obtidos com a ação administrativa". O autor observa que nem tudo o que se obtém por um custo reduzido atende bem a coletividade e, por isso, o controle da economicidade abrange o exame da despesa do ponto de vista da obtenção do resultado por um custo adequado, não necessariamente pelo menor (custo) possível.

O conceito de economicidade determina a otimização na articulação dos meios financeiros, e apesar de estar apenas inserido no Art. 70 da CFR/88, o princípio da economicidade pode ser considerado como um dos vetores fundamentais para a verificação da boa ou eficiente administração. Tal concepção associa-se à ideia fundamental de obter o melhor resultado estratégico possível a partir de determinada alocação de recursos econômico-financeiros, em dado cenário socioeconômico (BATISTA JÚNIOR, 2004).

No que tange ao princípio da economicidade, Pereira [200-] afirma que nos procedimentos licitatórios, especial- 
mente nos casos em que o critério de "menor preço" é utilizado, é comum a observância apenas deste fator (econômico). Dessa forma, pressupõe-se a partir da análise do autor que o princípio da eficiência seria negligenciado nesses casos, e os objetos adquiridos por meio dessas contratações corresponderiam a produtos de péssima qualidade.

Cabe ressaltar que, de acordo com Alexandrino e Paulo (2010), a ideia de eficiência aproxima-se da de economicidade, referindo-se esta última ao controle financeiro da administração pública. Segundo os autores, busca-se atingir os objetivos relativos à boa prestação de serviços utilizando-se o modo mais simples, mais rápido e mais econômico, de maneira que se melhore a relação custo/benefício da atividade da administração.

Sendo assim, destaca-se que "[...] o administrador deve sempre procurar a solução que melhor atenda ao interesse publico, levando em conta o ótimo aproveitamento dos recursos públicos, conforme essa análise de custos e benefícios correspondentes". (Alexandrino; Paulo, 2010, p. 204).

Logo, nota-se a existência de estreita relação entre os princípios da eficiência e economicidade. Atender apenas à exigência de baixos custos não implica a plena observância da economicidade, uma vez que são também exigidos padrões de eficiência para que se configure uma ação economicamente satisfatória.

Análise da relação entre os princípios da eficiência e economicidade nos contratos administrativos formalizados pela Secretaria de Estado de Turismo/MG (Setur)

Durante a etapa de análise dos contratos relacionados ao objeto do presente artigo, foram utilizados os documentos referentes aos processos de contratação da Setur, bem como os contratos celebrados pela Secretaria.

Inicialmente, realizou-se o levantamento dos contratos celebrados pelo órgão ao longo dos exercícios de 2008 e 2009, verificando-se, principalmente, a data de início de cada contrato, seu período de vigência, o serviço correspondente ao seu

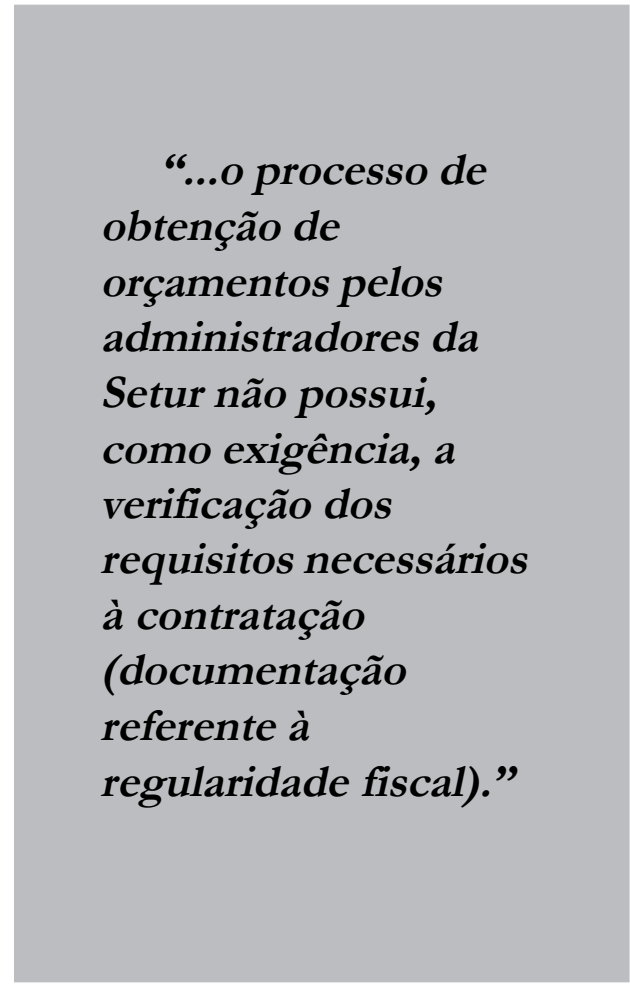

objeto, o valor da contratação realizada, e a responsabilidade das partes.

Em seguida, foram realizadas as entrevistas com os gestores de cada contrato ${ }^{1}$. As principais deduções advindas da utilização deste instrumento metodológico serão analisadas nesta seção à luz dos objetivos traçados por este artigo no que diz respeito ao princípio da eficiência. 
A partir dos dados analisados, foram também registrados os orçamentos relativos às pesquisas de mercado realizadas pelos administradores com vistas à verificação da observância do princípio da economicidade. No que diz respeito aos contratos em que tais pesquisas eram inviáveis, buscou-se a verificação da existência de consistente justificativa de preço.

Dessa forma, tendo em vista os contratos levantados durante a pesquisa, verificouse o cumprimento das obrigações da parte contratada, identificando quais gestores estão satisfeitos com a execução dos contratos sob sua responsabilidade. As cláusulas dos respectivos contratos constituíram a principal fonte das entrevistas realizadas.

Identificou-se, durante esse processo, a existência de gestores que se consideram incapazes de realizar o acompanhamento da execução contratual, uma vez que a prestação dos serviços contratados é feita em outra cidade. Dessa forma, a verificação do cumprimento de muitas das obrigações con- tratuais não é realizada por esses servidores e o cumprimento do dever de fiscalizar a execução contratual é comprometido.

Foram identificadas cláusulas que contêm termos vagos referentes às condições de cumprimento das obrigações contratuais. Exemplificando, a expressão "em tempo hábil", inserida em um dos contratos analisados, não possui um significado preciso por meio do qual se determine a quantidade de horas ou dias máximos necessários para que se considere que o serviço não foi prestado da forma acordada. Nesses casos, foi sugerido que tais termos fossem especificados durante a elaboração das cláusulas contratuais, de modo a favorecer a compreensão das obrigações de cada uma das partes.

Por meio do Quadro 1, foram agregados os principais resultados obtidos a partir das entrevistas. Em seguida, serão analisados separadamente cada um dos itens constantes do respectivo quadro com vistas à interpretação das respostas, tendo

\section{Quadro 1: Resultados obtidos a partir das entrevistas}

\begin{tabular}{|lcc|}
\hline $\begin{array}{l}\text { Aspecto analisado } \\
\text { por meio da entrevista } \\
\text { realizada }\end{array}$ & $\begin{array}{c}\text { Porcentagem de gestores } \\
\text { que responderam } \\
\text { positivamente }\end{array}$ & $\begin{array}{c}\text { Porcentagem de gestores } \\
\text { que responderam } \\
\text { negativamente }\end{array}$ \\
\hline $\begin{array}{l}\text { Facilidade para entrar em contato } \\
\text { com a empresa. }\end{array}$ & $92 \%$ & $8 \%$ \\
\hline $\begin{array}{l}\text { Obtenção da ajuda necessária ao } \\
\text { entrar em contato com a empresa. }\end{array}$ & $100 \%$ & $0 \%$ \\
\hline $\begin{array}{l}\text { Conformidade do serviço prestado } \\
\text { com o projeto básico. }\end{array}$ & $100 \%$ & $8 \%$ \\
\hline $\begin{array}{l}\text { Respeito aos prazos de entrega } \\
\text { estabelecidos. }\end{array}$ & $92 \%$ & $87 \%$ \\
\hline $\begin{array}{l}\text { Necessidade de aplicação de sanções } \\
\text { administrativas. }\end{array}$ & $13 \%$ & $8 \%$ \\
\hline $\begin{array}{l}\text { Inexistência de outro fator (não abordado } \\
\text { pela entrevista) capaz de gerar insatisfação. }\end{array}$ & $92 \%$ & $13 \%$ \\
\hline Satisfação no que tange ao serviço prestado. & $87 \%$ & $8 \%$ \\
\hline
\end{tabular}

Fonte:Entrevistas realizadas com servidores da Secretaria de Estado de Turismo de Minas Gerais. 
como foco o referencial teórico utilizado neste artigo.

No que tange ao contato com o representante da contratada, a maioria dos entrevistados declarou não ter tido dificuldades para entrar em contato com o representante da parte contratada. Além disso, os gestores alegam ter obtido a ajuda de que precisavam ao apresentar sua demanda ao referido representante. No entanto, importa observar que um dos entrevistados afirmou, nos seguintes termos, que "a empresa atende às solicitações da Secretaria, no entanto, há que se esperar por muito tempo até que a ajuda necessária seja providenciada". (Gestor 1)

Nota-se que apenas durante execução de poucos contratos, apesar de ser possível contatar o fornecedor responsável pelo serviço, a Setur é obrigada a esperar durante um período de tempo considerável até que tenha sua demanda atendida. Sendo assim, entende-se que tal prática, por parte de alguns fornecedores, afronta as determinações das cláusulas contratuais que dizem respeito aos prazos de reparação de danos decorrentes da prestação do serviço.

Entretanto, a maior parte dos pesquisados afirma não enfrentar dificuldades relativas ao desrespeito dos prazos normais de entrega estabelecidos no contrato. Durante as entrevistas declarou-se que: "os prazos de entrega foram sempre respeitados pela empresa, os serviços são prestados com notória pontualidade gerando grande satisfação quanto à execução deste contrato". (Gestor 15)

A totalidade dos entrevistados considera o serviço prestado compatível com aquele requisitado por meio do projeto básico. Dessa forma, em geral, pode-se inferir, a partir dos dados coletados, que os fornecedores têm o cuidado de prestar o serviço de acordo com as especificidades estabelecidas no edital de licitação.

É necessário destacar a existência de gestores que alegam ser o conhecimento das cláusulas contratuais uma responsabilidade da comissão de licitação, e não do próprio gestor. No entanto, entende-se ser imprescindível que o gestor de cada contrato possua tal conhecimento, visto que seu dever de fiscalizar a execução contratual só pode ser cumprido a partir da comparação entre o que foi inicialmente acordado por meio do instrumento contratual, e o que, de fato, é realizado.

Ao eximir-se da obrigação de conhecer o conteúdo do contrato, tais entrevistados demonstram que não estão aptos a desempenhar as atividades de fiscalização e acompanhamento contratual nos moldes legalmente estabelecidos.

A aplicação das sanções administrativas previstas nos art. 86 a 88 da Lei Federal no 8.666, de 21 de junho de 1993, não ocorreu durante a execução da maioria dos contratos. Mesmo nos casos em que se identifica o descumprimento de obrigações contratuais relativas aos prazos de entrega, em geral, as sanções administrativas não são aplicadas. Afirmou-se que

[...] não houve a notificação das empresas contratadas, mesmo havendo descumprimento de cláusulas contratuais, pois o ato de notificação é muito burocrático e moroso. Em contratos anteriores, pelo fato de a Setur ter notificado a parte contratada houve paralisação dos respectivos processos, prejudicando as atividades desenvolvidas pela Secretaria. Sendo assim, estabeleço um prazo para que a parte contratada realize as adequações necessárias e, se dentro deste prazo, a demanda da Secretaria não é atendida, a contratada é notificada pela Setur. 
Quanto aos contratos sob minha responsabilidade, as adequações foram, sempre, realizadas antes do término deste prazo, não havendo necessidade de notificar a empresa. (Gestor 24)

De fato, como expressa Almeida (2009, p. 25), “aos fornecedores que descumprirem total ou parcialmente os contratos celebrados com a Administração Pública Estadual, serão aplicadas as sanções previstas no Art. 87 da Lei Federal no 8.666, de 1993 [...]". Dessa forma, entende-se que, havendo desrespeito aos prazos de entrega, ou a qualquer outra exigência contratual, a Setur passa a ter o dever, e não a faculdade, de aplicar tais sanções ${ }^{2}$.

A maioria dos entrevistados não é capaz de identificar nenhum outro fator não abordado pelas perguntas - capaz de diminuir sua satisfação quanto à execução contratual. Observa-se, ainda, que a maior parte dos pesquisados afirma estar satisfeita com a prestação do serviço contratado. Nesse sentido, observou-se que grande parte dos gestores considera que os contratos sob sua responsabilidade atendem bem às demandas da Setur.

Constatou-se a existência de falhas no processo de execução contratual provenientes de etapas anteriores até mesmo à formalização do contrato, como a inadequada definição do objeto, ou mesmo das exigências constantes das cláusulas contratuais. Assim sendo, percebe-se que a satisfatória execução contratual depende não somente das atividades de fiscalização e acompanhamento exercidas pelo gestor, mas também de como foi conduzido o processo licitatório.

A comparação dos valores correspondentes aos orçamentos realizados durante a fase interna da licitação com os valores estabelecidos nos contratos foi feita para que se verificasse a aplicação do princípio da economicidade no contexto dos contratos analisados. O procedimento utilizado pela Secretaria para definir a estimativa e a justificativa de preço constantes do projeto básico baseia-se na obtenção de três orçamentos relativos ao objeto da contratação. A partir de tais orçamentos, calcula-se a média dos valores obtidos e, dessa forma, ocorre a simulação do preço de mercado correspondente ao objeto que a administração busca adquirir.

Faz-se necessário ressaltar que o cálculo da média dos orçamentos obtidos em cada pesquisa de mercado não considera a possibilidade de distorções decorrentes da heterogeneidade dos valores utilizados. Consequentemente, a interpretação das médias utilizadas pelos servidores da Setur como justificativa de preço de mercado deve considerar a grande influência de valores muito altos, ou muito baixos, no resultado obtido pela média aritmética calculada.

Foi possível constatar que o processo de obtenção de orçamentos pelos administradores da Setur não possui, como exigência, a verificação dos requisitos necessários à contratação (documentação referente à regularidade fiscal), de maneira que propostas com baixos valores podem ser enviadas por fornecedores que não preenchem os requisitos necessários à contratação com o Poder Público. Esse fator traduz a possibilidade de a pesquisa do preço de mercado ser, muitas vezes, ilusória, já que as propostas de orçamento a serem enviadas, caso sejam considerados os requisitos de contratação, podem ter valores bem mais elevados que aqueles constantes dos orçamentos obtidos.

Observa-se, a partir da análise do Gráfico 1, a porcentagem que representa a relação entre o valor de cada contrato e a média 
Gráfico 1: Valores dos contratos de prestação de serviço formalizados pela Secretaria de Estado Turismo de Minas Gerais (Setur) em relação às médias do mercado - Minas Gerais, 2008-2009

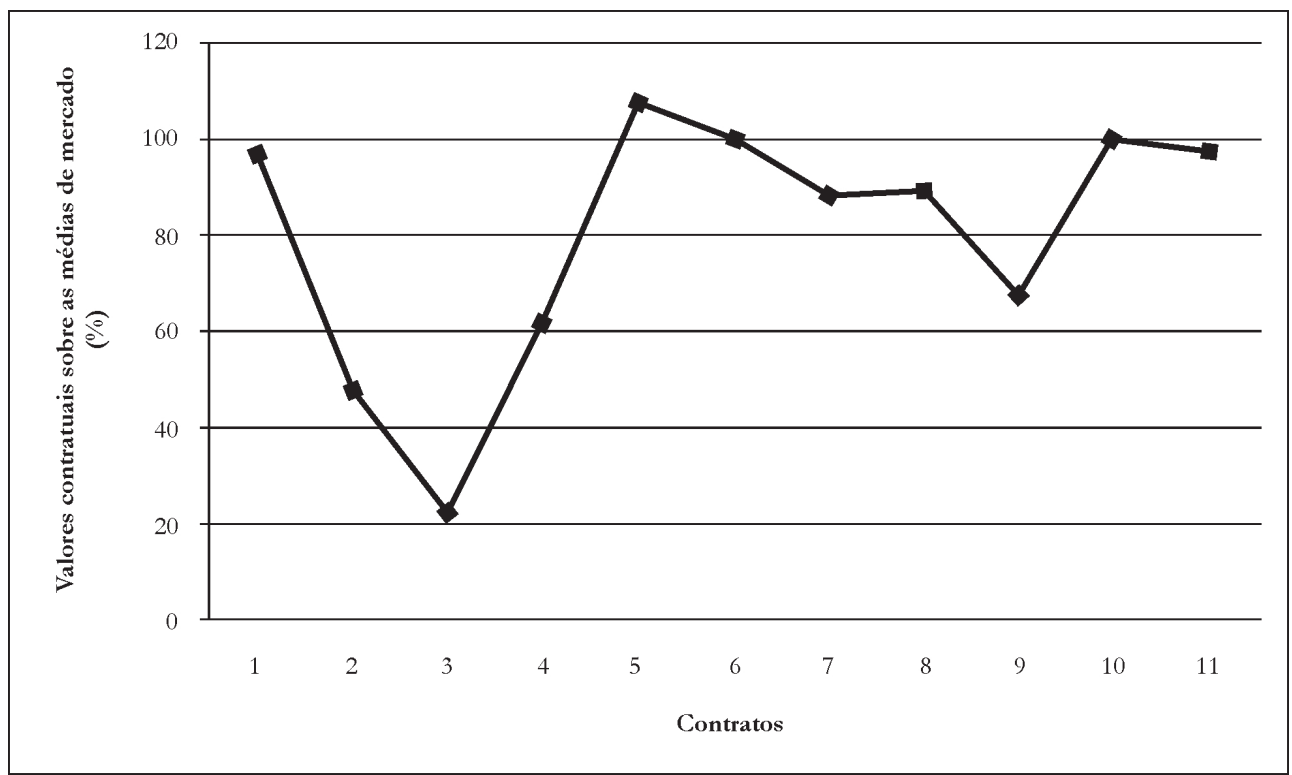

Fonte: Secretaria de Estado de Turismo de Minas Gerais (Setur). Diretoria de Logística e Manutenção.

Nota: Entre os 18 processos disponíveis para a análise das pesquisas de preços realizadas, apenas 11 são baseados em justificativas de preço quantitativas.

de mercado referente ao seu objeto (valor contratual sobre média de mercado). Os dados apresentados evidenciam a preponderância de valores de contratação inferiores ou equivalentes às médias relativas aos orçamentos levantados pela Secretaria.

Logo, sob o ponto de vista econômico, observa-se, de uma forma geral, o adequado aproveitamento dos recursos financeiros à disposição da Setur. A análise realizada sugere que a referida Secretaria, ao celebrar seus contratos, assume obrigações de pagamento em conformidade com os preços praticados no mercado.

Nota-se, a partir dos dados coletados, a existência de alguns valores de contratação extremamente inferiores aos identificados por meio das pesquisas de preço realizadas na fase interna do processo licitatório.
É possível observar que em uma pequena parte dos contratos analisados a Secretaria pagou preços extremamente inferiores às médias de mercado, em determinados casos as despesas associadas a esses serviços sofreram uma queda superior a $50 \%$. No entanto, alguns pesquisados consideram esses casos "péssimas contratações", uma vez que os serviços prestados pela empresa contratada não atendem às necessidades da Setur. Frente a essa situação, a Secretaria notificou parte dos particulares responsáveis pela prestação dos serviços.

Nessa perspectiva, entende-se que contratos vantajosos para a Setur não podem ser definidos como aqueles cujos valores pagos são baixos em relação aos preços praticados no mercado. É também necessário 
que sejam observados os requisitos de eficiência ao longo da execução contratual.

Nos contratos em que as pesquisas de preço não eram viáveis em razão de fatores associados à natureza do serviço desejado, foi verificada a existência de justificativas de preço, muitas vezes baseadas em dispositivos legais, capazes de comprovar que o valor do contrato é compatível com o preço atribuído ao serviço no mercado. Desse modo, constatou-se, no âmbito dos contratos, a observância dos pressupostos referentes ao conceito de economicidade.

Entretanto, nos poucos casos em que houve descumprimento de obrigações contratuais e valores muito baixos foram pagos aos fornecedores, não se pôde verificar a observância de tais princípios visto que, segundo Nagel (apud Fernandes, 2008, p. 49), “[...] nem tudo o que é de custo reduzido atende bem à coletividade".

Nessa perspectiva, ainda que nos poucos contratos considerados ineficientes por seus gestores fosse verificado o pagamento de um baixo valor de contratação, em relação ao valor praticado no mercado, não seria possível constatar a existência de observância do princípio da economicidade, visto que não seria verificada a adequada relação custo-benefício inerente ao princípio.

Pode-se, inicialmente, inferir que, na maioria dos contratos, verificou-se a existência de conformidade com os princípios da economicidade e da eficiência, uma vez que, além de verificar a satisfação dos gestores frente à execução contratual, observou-se, de modo geral, a compatibilidade dos valores dos contratos com os preços praticados no mercado.

\section{Conclusão}

Tendo em vista os objetivos iniciais do artigo, referentes à verificação de sobreposição do princípio da economicidade sobre o da eficiência nos contratos celebrados pela Setur durante os exercícios de 2008 e 2009, nota-se, a partir da análise realizada a respeito desses princípios, que o princípio da eficiência possui entre seus pressupostos a exigência de adequada aplicação dos recursos públicos em seu sentido econômico, e que o princípio da economicidade não se esgota na simples análise de justificativa do valor do objeto contratado.

Retomando-se o entendimento de Fernandes (2008), pode-se inferir que um serviço contratado a baixo custo, não necessariamente atende bem aos cidadãos. $\mathrm{O}$ valor de um contrato administrativo pode, então, ser extremamente baixo comparativamente ao valor praticado no mercado e, mesmo assim, ser capaz de afrontar o princípio da economicidade, caso os aspectos referentes à eficiência - tendo em vista a busca do interesse público - não estejam presentes em tal contratação. Paralelamente, observa-se que para que a administração atenda ao princípio da eficiência é também exigida uma adequada relação custo-benefício no que diz respeito à alocação dos recursos públicos.

Sendo assim, entende-se ser indissociável a relação entre os princípios em comento, de forma que um contrato administrativo não pode ser eficiente sem ser econômico e vice-versa. Nessa perspectiva, ao analisar as características dos contratos que constituem objeto do artigo, buscou-se verificar a existência de maior ou menor ênfase dada a qualquer um desses princípios, no âmbito da Setur, e não a total observância de um deles em detrimento do outro.

Ao contrário do que poderia ser previsto a partir da já mencionada análise de Pereira [200-] - ponto de vista que sugere a existência de predominância de contratações 
ineficientes na administração pública -, a maior parte dos gestores entrevistados afirmou estar satisfeita com a prestação dos serviços contratados pela Setur.

No que diz respeito à análise da aplicação do princípio da economicidade nos contratos, conclui-se que os valores acertados pela Secretaria, na maior parte dos casos, não ultrapassaram os limites estabelecidos pelas pesquisas de mercado realizadas. Essa afirmativa é capaz de demonstrar que, havendo sido feitas de forma adequada cada uma das pesquisas, a Setur agiu, nesses casos, de forma a obter contratações vantajosas sob o ponto de vista econômico, tendo em vista as orientações do TCU previamente citadas.

Destaca-se, ainda, a partir dos casos analisados, a necessidade de aprimorar os processos de elaboração das cláusulas contratuais na referida Secretaria, de forma a estabelecer critérios objetivos de análise do cumprimento das obrigações contratuais. Além disso, é importante que os gestores responsáveis pelo contrato possuam os conhecimentos técnicos específicos necessários à compreensão desses critérios e ao adequado acompanhamento da execução contratual.

Observou-se, em alguns casos analisados neste artigo, que a aplicação das sanções legalmente previstas não ocorre em situações em que há inexecução total ou parcial do contrato, tendo em vista o conteúdo de suas cláusulas. Tal procedimento é capaz de comprometer a eficiência da execução dos contratos da Setur, visto que a parte contratada não terá incentivos suficientes para adequar sua prestação de serviços às exigências contratuais. Assim sendo, o interesse público envolvido nos serviços é comprometido, sem que a administração se utilize dos instrumentos concedidos a ela, por meio da Lei Federal no 8.666, de 21 de junho de 1993, para punir a parte contratada pelas irregularidades praticadas ao longo da execução contratual.

Entende-se, também, ser necessário questionar a efetividade das pesquisas de mercado realizadas durante a fase interna do processo licitatório, uma vez que a inadequada mensuração do valor praticado no mercado - referente ao serviço a ser ad-

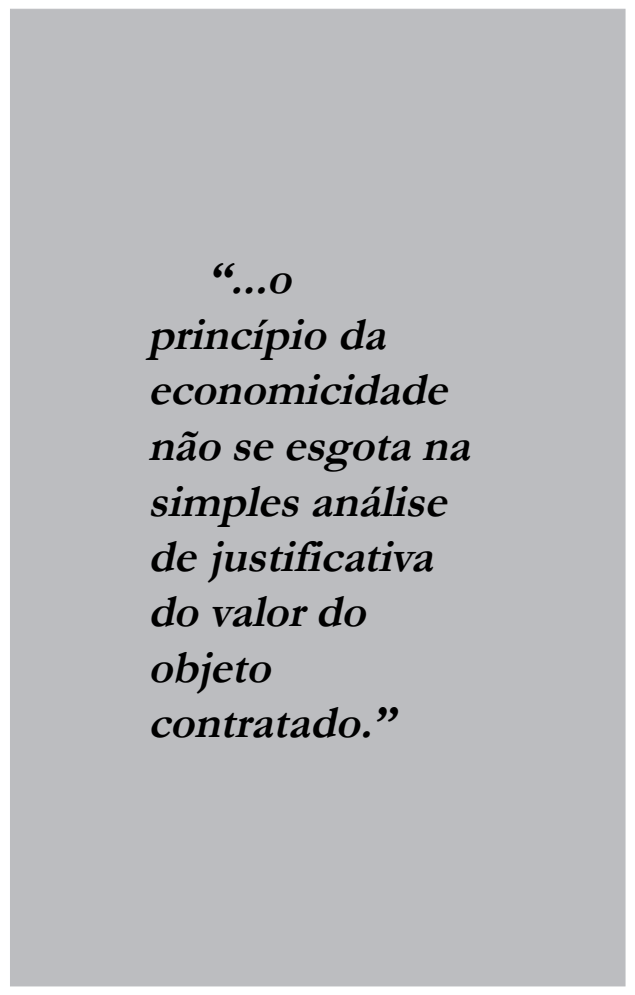

quirido pela Setur - pode provocar o comprometimento do objetivo de selecionar a proposta mais vantajosa para a administração, finalidade prevista no Art. $3^{\circ}$ da Lei Federal no 8.666, de 21 de junho de 1993.

Assim sendo, nota-se, ao longo do estudo realizado, a existência de diversos pontos a serem desenvolvidos pela Setur no âmbito do processo de execução contratual - especificamente no que se refere aos contratos de prestação de servi- 
ços -, no que diz respeito, principalmente: ao domínio do conteúdo do contrato por parte de seu gestor; ao processo de realização das pesquisas de mercado; e à aplicação das sanções administrativas legalmente previstas.

No entanto, foram também identificados fatores positivos no contexto dos contratos analisados, dentre os quais se faz necessário destacar: a satisfação da maioria dos gestores em relação aos serviços prestados pelas contratadas e a existência, na maioria dos casos analisados, de valores de contratação inferiores às médias calculadas referentes aos preços praticados no mercado para a compra do mesmo objeto.

Faz-se, todavia, necessário observar que a satisfação do gestor no que diz respeito à execução contratual deve ser analisada juntamente com a verificação do ponto de vista do usuário final do serviço, posto que se observou, ao longo da pesquisa, que a avaliação do gestor do contrato pode divergir de forma considerável daquela realizada por quem de fato utiliza o serviço contratado.

A partir das conclusões obtidas, entende-se adequado introduzir mecanismos de avaliação periódica dos fornecedores no âmbito da Setur, tendo em vista a percepção de eventuais descumprimentos de obrigações contratualmente estipuladas. A formalização de tais procedimentos de avaliação poderia contribuir para a identificação da necessidade de aplicação das sanções legalmente previstas, bem como para o aprendizado da administração no que diz respeito à sua relação com seus contratados.

Dessa forma, sugere-se que os processos de avaliação não se limitem à verificação da satisfação dos gestores contratuais, os quais diversas vezes não são os usuários do serviço prestado. É importante que o destinatário final do serviço contratado seja abordado por meio de uma pesquisa de satisfação que vise avaliar a eficiência da execução contratual. O resultado dessa pesquisa seria, então, encaminhado ao gestor do respectivo contrato para que fossem adotadas, em cada caso, as providências necessárias.

A comissão de licitação, da mesma forma, teria acesso a tais resultados, os quais poderiam orientar a realização de licitações futuras cujos objetos fossem similares aos anteriormente contratados. Sendo assim, o processo de elaboração do edital e, especificamente, das cláusulas contratuais seria aprimorado a partir da melhor compreensão das demandas e dos questionamentos dos usuários acerca dos serviços a serem contratados.

Destaca-se, ainda, a importância de investir no treinamento e na preparação dos diversos gestores contratuais. Tais ações tornam-se necessárias na medida em que a compreensão inadequada dos deveres como gestor assim como a falta de conhecimento técnico sobre o objeto do contrato sob sua responsabilidade podem comprometer o sucesso da execução contratual, resultando em perdas de eficiência nas atividades desenvolvidas pela administração.

Finalmente, destaca-se a necessidade de que outros trabalhos analisem a aplicação do tema deste estudo nos demais órgãos e esferas governamentais, com vistas à elaboração de índices de satisfação capazes de mensurar o nível de eficiência dos contratos celebrados pela administração pública. $\mathrm{O}$ aprendizado decorrente da realização desses trabalhos tem o potencial de proporcionar ao Estado meios para que garanta a efetividade da aplicação de diversos princípios da reforma gerencial na prática administrativa.

(Artigo recebido em janeiro de 2011. Versão final em fevereiro de 2012). 


\section{Notas}

${ }^{1}$ As entrevistas foram feitas durante o período de 2 de março a 13 de abril de 2010, sendo que, entre os 27 gestores responsáveis pelos contratos em análise, três não se encontraram disponíveis para a realização das entrevistas e, por isso, não responderam às perguntas elaboradas. Cada gestor é identificado, ao longo do artigo, por meio de números escolhidos aleatoriamente de forma a preservar sua identidade.

${ }^{2}$ Ao considerar o estabelecimento do prazo para que a empresa se adeque às exigências contratuais como uma notificação, apesar de o gestor 24 ter informado que não aplicou sanções durante a execução contratual, pode-se inferir que tal aplicação ocorreu no momento em que o prazo foi estabelecido.

\section{Referências bibliográficas}

Abrucio, Fernando Luiz. Trajetória recente da gestão pública brasileira: um balanço crítico e a renovação da agenda de reformas. Revista de Administração Pública, Rio de Janeiro, Edição especial comemorativa, p. 67-86, 2007.

Alcantara, Christian Mendes. Os princípios constitucionais da eficiência e eficácia da administração pública: estudo comparativo Brasil e Espanha. Constituição, Economia e Desenvolvimento: Revista da Academia Brasileira de Direito Constitucional, Curitiba, n. 1, p. 24-49, ago./dez. 2009.

Alexandrino, Marcelo; Paulo, Vicente de. Direito administrativo descomplicado. Rio de Janeiro: Forense; São Paulo: Método, 2010. 954 p.

Alexy, Robert. On the structure of legal principles. Ratio Juris, v. 13, n. 3, set. 2000.

Almeida, Betânia Lourenço S. de. Curso de capacitação em gestão de contratos. Belo Horizonte: Fundação João Pinheiro, Escola de Governo Professor Paulo Neves de Carvalho, 2009. $41 \mathrm{p}$.

Ávila, Humberto. Teoria dos princípios: da definição à aplicação dos princípios jurídicos. 4. ed. São Paulo: Malheiros, 2005.

Batista Júnior, Onofre Alves. Princípio constitucional da eficiência administrativa. Belo Horizonte: Mandamentos, 2004. 776 p.

Brasil. Lei no 8.666, de 21 de junho de 1993. Regulamenta o artigo 37 da Constituição Federal, institui normas para licitações e contratos da Administração Pública e dá outras providências. 1993. Disponível em < http://www.planalto.gov.br>. Acesso em: 23 nov. 2009.

Tribunal de Contas da União. Licitações e contratos: orientações básicas. 3. ed. rev. atual. e ampl. Brasília, 2006.

Senado, 2007.

Constituição (1988). Constituição da República Federativa do Brasil. Brasília: 
Bruno, Reinaldo Moreira. Direito administrativo didático. Belo Horizonte: Del Rey, 2008. Bugarin, Paulo Soares. O princípio constitucional da economicidade. Correio Braziliense, Brasília, [199-]. Disponível em: <http://www.buscalegis.ufsc.br / revistas/ index.php/ buscalegis/article/viewFile/14156/13721>. Acesso em: 29 set. 2009.

Coelho, Daniela Mello. Administração pública gerencial e direito administrativo. Belo Horizonte: Mandamentos, 2004.

Di Pietro, Maria Sylvia Zanella. Direito administrativo. 10. ed., São Paulo: Atlas, 1999.

Fernandes, J. U. Jacoby. Tribunal de Contas do Brasil: jurisdição e competência. Belo Horizonte: Fórum, 2008.

FRANÇA, Vladimir da Rocha. Questões sobre a hierarquia entre as normas constitucionais na CF/88. Jus Navigandi, Teresina, ano 3, n. 33, jul. 1999. Disponível em: < http:// jus2.uol.com.br/doutrina/texto.asp?id=135>. Acesso em: 2 dez. 2009.

JucÁ, Maria Carolina Miranda. Crise e reforma do Estado: as bases estruturantes do novo modelo. Jus Navigandi, Teresina, ano 7, n. 61, jan. 2003. Disponível em: <http:// jus2.uol.com.br/doutrina/texto.asp?id=3598>. Acesso em: 2 dez. 2009.

Justen Filho, Marçal. Curso de direito administrativo. 2. ed. rev. e atual. São Paulo: Saraiva, 2006. 851 p.

Martins, Cristiane Fortes Nunes. O Princípio da Eficiência na Administração Pública. [S.l.: s.n., 200-]. Disponível em: <http://www.buscalegis. ufsc.br/ revistas /index.php/ buscalegi s/article/viewFile/32602/31811> Acesso em: 30 nov. 2009.

MeIrelles, Hely Lopes. Licitação e contrato administrativo. São Paulo: Malheiros, 2007. 482 p.

Mello, Celso Antônio Bandeira de. Curso de direito administrativo. São Paulo: Malheiros, 2004. 960 p.

Pereira, Celina. Discricionariedade, eficiência e controle dos atos administrativos. $2^{\circ}$ Concurso de Monografias da CGU, Belo Horizonte, 2007. Disponível em: <http://www.esaf. fazenda.gov.br/esafsite/premios/CGU/monografia-2007/Universitari os/2-18 EG/ Monografia_corpo.pdf $>$ Acesso em: 13 out. 2010.

Pereira, Luiz Carlos Bresser Gonçalves; SPINK, Peter Kevin. Reforma do Estado e administração pública gerencial. Rio de Janeiro: FGV, 2006.

Pereira, Vanusa Batista. O princípio da economicidade no âmbito das licitações públicas. [S.l.: s.n., 200-]. Disponível em: < http:/ / www.contabilidadeamazonia. com. br /artigos/artigo_22 economicidade.pdf $>$ Acesso em: 30 nov. 2009.

Silva, Virgilio Afonso da. Princípios e regras: mitos e equívocos acerca de uma distinção. Revista Latino Americana de Estudos Constitucionais, Belo Horizonte, n. 1, p. 607 631, jan./jun. 2003.

SZKLAROwSKY, Leon Frejda. Interpretação dos contratos administrativos. Jus Navigandi, Teresina, ano 4, n. 36, nov. 1999. Disponível em: <http://jus2.uol.com.br / doutrina/ texto.asp?i d=458>. Acesso em: 2 dez. 2009. 
Timm, Luciano Benetti; Toniolo, Giuliano. A aplicação do princípio da eficiência à administração pública: levantamento bibliográfico e um estudo da jurisprudência do TJRS. Salvador, n. 18, jun./jul./ago. 2003. Disponível em: <http://www.direitodoestado. com/revista/ RERE-18-JUNHO-2009-LUCIANO-BENETTI.pdf> Acesso em: $1^{\circ}$ dez. 2009. 


\section{Resumo - Resumen - Abstract}

A relação entre os princípios da eficiência e da economicidade nos contratos administrativos

Maria Isabel Araíjo Rodrigues e Letícia Malta Araujo

Este artigo visa averiguar a ocorrência ou não de sobreposição do princípio da economicidade ao da eficiência nos contratos administrativos firmados pela Secretaria de Estado de Turismo de Minas Gerais, durante os exercícios de 2008 e 2009. Buscou-se, inicialmente, o embasamento legal e teórico acerca dos contratos e licitações no âmbito do Direito Administrativo, bem como dos princípios da administração pública. Foram realizados o levantamento e a análise dos contratos de prestação de serviços firmados pela Secretaria utilizando-se de entrevistas e da comparação entre os valores dos contratos e os preços de mercado identificados por esse órgão. A partir das análises, constatou-se, na maioria dos contratos, a observância dos princípios da eficiência e da economicidade. Verificou-se, ainda, que a ligação entre tais princípios deve, necessariamente, ocorrer no contexto dos contratos administrativos, uma vez que a observância de um deles não se configura plenamente quando existe desconformidade com o outro. Foram realizadas sugestões acerca do desenvolvimento dos processos de execução e fiscalização contratual, sendo enfatizada a necessidade de aplicação de técnicas de avaliação dos níveis de eficiência correspondentes aos contratos celebrados pela administração pública.

Palavras-chave: contratos administrativos, princípio da eficiência, princípio da economicidade.

\section{La relación entre los principios de la economía y de la eficiencia en los contratos administrativos \\ Maria Isabel Araíjo Rodrigues y Letícia Malta Aranjo}

Este artículo tiene como objetivo verificar si hay preferencia por uno de los principios de la economía y de la eficiencia en los contratos administrativos firmados por la Secretaría de Estado de Turismo de Minas Gerais durante 2008 y 2009. Fue presentada la teoría acerca de los contratos y licitaciones en el ámbito del Derecho Administrativo, así como de los principios de la Administración Pública. Fueron analizados los contratos de préstamo de servicios firmados por la secretaría utilizándose de entrevistas y de la comparación entre los valores de los contratos y los precios de mercado identificados. Se constató, en la mayoría de los contratos, la existencia de los principios de la eficiencia y de la economia. Se verificó que la conección entre los principios debe ocurrir en el contexto de los contratos administrativos, una vez que la observancia de uno de ellos no se configura plenamente cuando existe desconformidad con el otro. Fueron realizadas sugerencias acerca del desarrollo de los procesos de ejecución y fiscalización contractual, siendo enfatizada la necesidad de aplicación de técnicas de evaluación de la eficiencia en los contratos celebrados por la Administración Pública.

Palabras clave: administración pública, licitación, contratos administrativos, principio de la eficacia, principio de la economía. 


\section{The relationship between the principles of economy and efficiency in administrative contracts}

Maria Isabel Araijo Rodrigues and Letícia Malta Aranjo

This article attempts to verify and examine the preferential usage of the economic principle over the efficiency principle in regards to the administrative contracts established by the Minas Gerais Secretary of Tourism during the administration period of 2008 and 2009. In order to support this claim, the documental and bibliographical research techniques were used to obtain legal and theoretical fundamentals regarding the contracts and biddings in the scope of Administrative Law, as well as Public Administration. Service contracts endorsed by the State Secretary were subject to a depth analysis that conveyed interviews with personnel, as well as comparison and contrast between contract values and the market prices approved by the Secretary. According to the data provided by the analysis, the presence of the economic and efficiency principles were evident in the majority of the contracts. The data collected demonstrated that the connection between these principles must necessarily occur in the administrative contracts context due their interdependence and mutual requirements for coexistence. Improvements for contractual execution and verification were suggested throughout this monograph by emphasizing the necessity for evaluation on correspondent efficiency levels of contracts negotiated by Public Administration.

Keywords: public administration, bidding, administrative contracts, efficiency principle, economic principle.

Letícia Malta Araújo

Graduada em Administração Pública, pela Fundação João Pinheiro (FJP). Contato: lelezinhamalta@yahoo.com.br

Maria Isabel Araújo Rodrigues

Mestre em Administração Pública pela Fundação João Pinheiro (FJP), graduada em Direito pela Universidade FUMEC Fundação Mineira de Educação e Cultura, e em Administração Pública pela Fundação João Pinheiro. Atualmente é Coordenadora do Colegiado do Curso de Administração Pública da Escola de Governo Professor Paulo Neves de Carvalho, da FJP. Contato: isabel.rodrigues@fjp.mg.gov.br 